\title{
Contribution from geriatric medicine within acute medical wards
}

\author{
LINDSAY E BURLEY，C T CURRIE， R G SMITH，J WILLIAMSON
}

British Medical fournal, 1979, 2, 90-92

\section{Summary and conclusions}

In 1977 a scheme of attachment to acute medical wards of consultants in geriatric medicine and associated junior medical staff was instituted in a large Edinburgh teaching hospital. The effect on admissions of patients aged 65 and over was examined for comparable periods before and during this arrangement. Mean and median stays were reduced for both sexes but more noticeably for women. The mean stay for all women aged over 65 was reduced from 25 to 16 days and for women aged over 85 from 50 to 19 days. The proportion staying under two weeks was significantly increased in both sexes, and the proportion discharged home also increased, correspondingly fewer patients being transferred to convalescent wards.

These changes were not accompanied by increased transfers to the geriatric department, and probably the skills and extra resources available to the geriatric service were the factors mainly responsible for the changes in performance.

\section{Introduction}

Since July 1977 each medical ward in a large Edinburgh teaching hospital has had an attached consultant in geriatric medicine. We attempt here to evaluate this arrangement as it affected the two male and two female wards with which the department of geriatric medicine has been associated.

The pattern of working that has evolved is as follows. One of the honorary consultants visits each ward weekly, generally accompanied by the registrar or honorary senior registrar in geriatric medicine. All new patients aged 65 and over are rapidly reviewed with the ward medical staff and ward sister or staff nurse. Patients with selected "geriatric features" (multiple disorders, social problems, mental disturbance, difficulty with locomotion, incontinence) are then discussed in detail and seen by the consultant. A discussion is then held with the medical social worker to ensure that relevant information about family, neighbours, and housing conditions is rapidly obtained and the physiotherapist and occupational therapist are asked to carry out their functional assessments where this seems relevant. Even at this early stage a programme of rehabilitation is being evolved and arrangements made to ensure the patient's earliest discharge with optimum facilities for aftercare and community support.

Once the new patients have been dealt with existing patients who have already been seen (including any discharged since the last visit) are reviewed at a case conference attended by the geriatric medicine consultant, medical staff from the ward, a nurse, physiotherapist, occupational therapist, and medical social

\footnotetext{
University Department of Geriatric Medicine, City Hospital, Edinburgh EH10 5SB

LINDSAY E BURLEY, MB, MRCP, registrar (now senior registrar, Eastern General Hospital, Edinburgh)

C T CURRIE, MB, MRCP, senior lecturer

R G SMITH, MB, MRCP, senior lecturer

$\mathrm{J}$ WILLIAMSON, MB, FRCPED, professor of geriatric medicine
}

worker. Progress is recorded and emphasis is again on planning effective aftercare. For the two male wards, of 30 and 25 beds, and two female wards, of 28 beds each, this commitment entails two or three consultant sessions a week and similar time from geriatric junior medical staff. This is no small contribution from the department of geriatric medicine, and it is therefore important to determine what effect it has had.

\section{Method}

We studied admissions of patients aged 65 and over to the four wards during December 1975 to July 1976 and December 1977 to July 1978. These periods represented "normal working" before and after the scheme was instituted. Mean and median stays in the ward; numbers of patients staying less than one week, one to two weeks, etc; destination on discharge; and deaths were recorded for both sexes.

\section{Results}

Analysis of the total numbers and age distribution of patients admitted to the four wards showed little difference between the two periods (table I). During the $1977-8$ period 420 men and 446 women aged over 65 were admitted. Of these, $255(61 \%)$ and $314(70 \%)$ respectively were seen by a geriatric consultant, the proportion increasing with age in both sexes and reaching $83 \%$ for the oldest women (table II).

TABLE I-Numbers of patients admitted to the four wards (two male, two female) during the two study periods (percentages in parentheses)

\begin{tabular}{ccccccc}
\hline \multirow{2}{*}{$\begin{array}{c}\text { Age group } \\
\text { (years) }\end{array}$} & \multicolumn{3}{c}{$1975-6$} & & \multicolumn{2}{c}{$1977-8$} \\
\cline { 2 - 3 } \cline { 5 - 6 } \cline { 5 - 6 } & \multicolumn{2}{c}{ Men } & Women & & Men & Women \\
\hline$<65$ & $679(64 \cdot 2)$ & $473(49 \cdot 7)$ & & $683(61 \cdot 9)$ & $487(52 \cdot 2)$ \\
$\geqslant 65$ & $378(35 \cdot 8)$ & $478(50 \cdot 3)$ & & $420(38 \cdot 1)$ & $446(47 \cdot 8)$ \\
\hline Total & $1057(100 \cdot 0)$ & $951(100 \cdot 0)$ & & $1103(100 \cdot 0)$ & $933(100 \cdot 0)$
\end{tabular}

TABLE II-Proportions of patients admitted to the four wards during 1977-8 who were seen by geriatric consultants

\begin{tabular}{lccccc}
\hline & \multicolumn{4}{c}{ Age group (years) } & \multirow{2}{*}{ Total } \\
\cline { 2 - 5 } & & $65-74$ & $75-84$ & $\geqslant 85$ & \\
\hline No $(\%)$ of men & $\cdots$ & $162(57 \cdot 0)$ & $75(65 \cdot 8)$ & $18(81 \cdot 8)$ & $255(60 \cdot 7)$ \\
No $(\%)$ of women & $\cdots$ & $141(65 \cdot 6)$ & $128(72 \cdot 3)$ & $45(83 \cdot 3)$ & $314(70 \cdot 4)$ \\
\hline
\end{tabular}

\section{DURATION OF STAY IN WARDS}

The main effect of the scheme on ward stay occurred in the numbers of patients staying under two weeks (see figure). Of the men aged 65 and over, $242(64 \%)$ stayed under two weeks in 1975-6 compared with $299(71 \%)$ in 1977-8. This difference was significant $\left(\chi^{2}\right.$ test: $P<$ $0.05)$. For women the corresponding figures were $221(46 \%)$ in $1975-6$ and $262(59 \%)$ in $1977-8(P<0.001)$.

The distribution of stay was very positively skewed (figure), and hence mean stay was inappropriate for comparison. Nevertheless, mean stay is widely used in inpatient statistics, and table III gives the mean durations of stay in our series. Mean stay was shorter in all age groups in the 1977-8 period, the reduction being most pronounced in women and the oldest age groups. In women aged 85 and over mean stay was reduced from 50 to 19 days. Because of the skewed distribution 
standard deviations and tests of significance were inapplicable to these means, and hence we used median stay $\pm 95 \%$ confidence limits (non-parametric). Table IV gives the results. For all groups except men aged 75-84 median stay was shorter in 1977-8 than in 1975-6. For men the differences were not significant, but for women of all ages over 65 the difference was almost three days, which was significant at $\mathrm{P}<0.05$.
FATE OF PATIENTS LEAVING ACUTE WARDS

A larger proportion of patients were discharged home in 1977-8 than in 1975-6 (table V), but the difference was most noticeable for women. Fewer patients were transferred to convalescent wards, and there was little change in the proportion transferred to other hospital units. Interestingly the proportions transferred to geriatric care

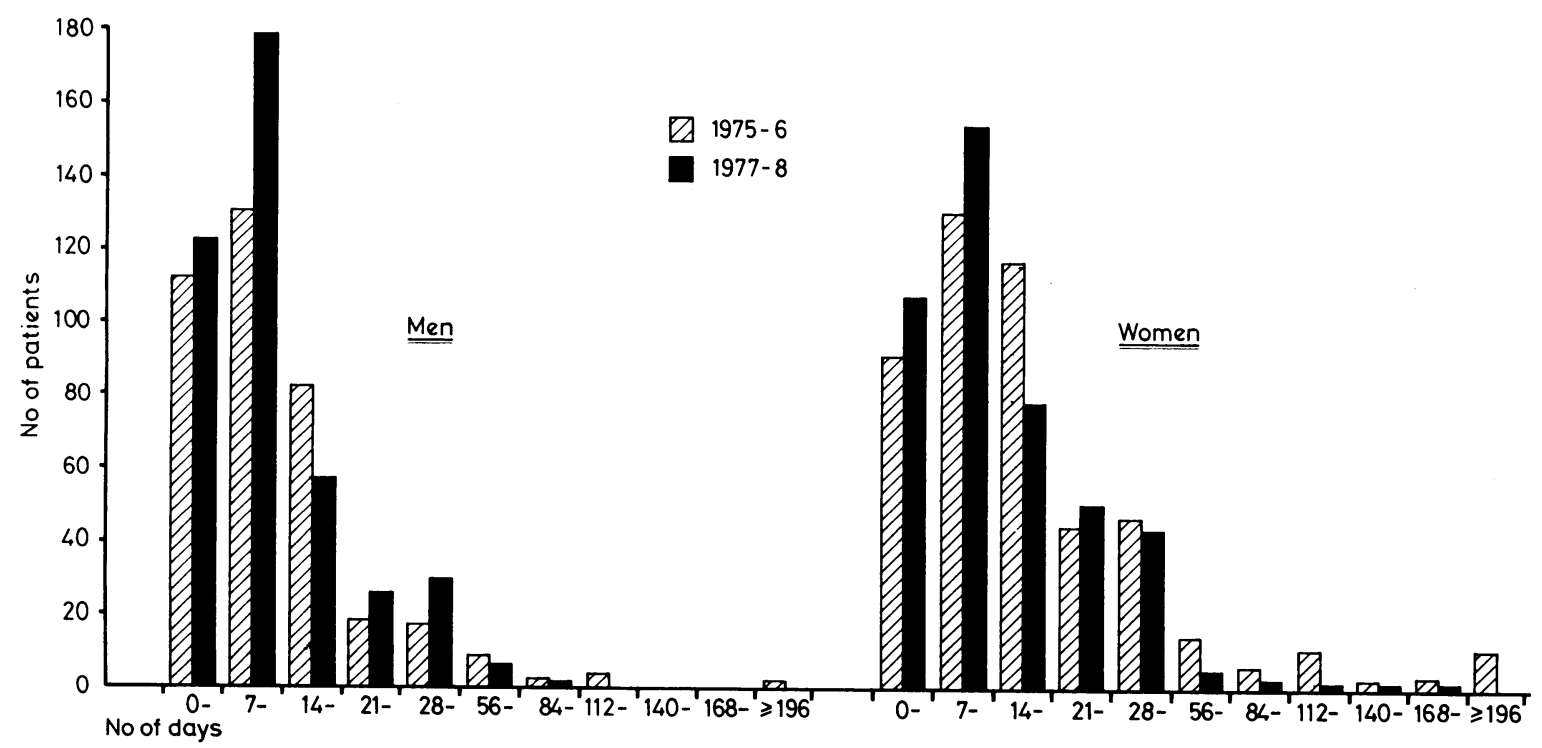

Durations of ward stay (days) during 1975-6 and 1977-8 study periods of all patients aged 65 and over.

TABLE III-Mean durations of ward stay (days) of all patients aged over 65 during the two study periods

\begin{tabular}{|c|c|c|c|c|}
\hline \multirow{2}{*}{$\begin{array}{l}\text { Age group } \\
\text { (years) }\end{array}$} & \multicolumn{2}{|c|}{$1975-6$} & \multicolumn{2}{|c|}{$1977-8$} \\
\hline & Men & Women & Men & Women \\
\hline $\begin{array}{c}65-74 \\
75-84 \\
\geqslant 85\end{array}$ & $\begin{array}{l}13 \cdot 6 \\
17 \cdot 2 \\
22 \cdot 7\end{array}$ & $\begin{array}{l}19 \cdot 4 \\
23.9 \\
49 \cdot 5\end{array}$ & $\begin{array}{l}12 \cdot 3 \\
15 \cdot 8 \\
12 \cdot 9\end{array}$ & $\begin{array}{l}14 \cdot 6 \\
17 \cdot 9 \\
19 \cdot 2\end{array}$ \\
\hline Total & $15 \cdot 2$ & $25 \cdot 4$ & $13 \cdot 3$ & $16 \cdot 5$ \\
\hline
\end{tabular}

TABLE IV-Median durations of stay $\pm 95 \%$ confidence limits (non-parametric) of all patients aged over 65 during the two study periods

\begin{tabular}{|c|c|c|c|c|c|c|}
\hline \multirow[b]{2}{*}{$\begin{array}{l}\text { Age } \\
\text { group } \\
\text { (years) }\end{array}$} & \multicolumn{2}{|c|}{$1975-6$} & \multicolumn{2}{|c|}{$1977-8$} & \multirow[b]{2}{*}{$\begin{array}{c}\text { Significance } \\
\text { of difference } \\
\text { between years }\end{array}$} & \multirow[b]{2}{*}{$\begin{array}{c}\text { Shorter } \\
\text { stay in } \\
1977-8 \text { ? }\end{array}$} \\
\hline & $\begin{array}{c}\text { No of } \\
\text { patients }\end{array}$ & $\begin{array}{c}\text { Median } \\
\text { stay } \\
\text { (days) }\end{array}$ & $\begin{array}{c}\text { No of } \\
\text { patients }\end{array}$ & $\begin{array}{c}\text { Median } \\
\text { stay } \\
\text { (days) }\end{array}$ & & \\
\hline \multicolumn{7}{|c|}{ Men } \\
\hline $65-74$ & 244 & $\left\{\begin{array}{l}11.3 \\
12.5\end{array}\right.$ & 284 & $\left\{\begin{array}{l}10 \cdot 3 \\
11 \cdot 2\end{array}\right.$ & NS & Yes \\
\hline $75-84$ & 115 & $\left\{\begin{array}{r}8.9 \\
11 \cdot 0 \\
13 \cdot 1\end{array}\right.$ & 114 & $\left\{\begin{array}{r}9 \cdot 5 \\
11 \cdot 3 \\
13 \cdot 1\end{array}\right.$ & NS & No \\
\hline$\geqslant 85$ & 19 & $\left\{\begin{array}{r}9 \cdot 8 \\
15 \cdot 8 \\
27 \cdot 0\end{array}\right.$ & 22 & $\left\{\begin{array}{r}6.0 \\
11.5 \\
17.5\end{array}\right.$ & NS & Yes \\
\hline Total & 378 & $\left\{\begin{array}{l}10 \cdot 1 \\
11 \cdot 2 \\
12 \cdot 2\end{array}\right.$ & 420 & $\left\{\begin{array}{r}9.7 \\
10.5 \\
11.3\end{array}\right.$ & NS & Yes \\
\hline \multicolumn{7}{|c|}{ Women } \\
\hline $65-74$ & 215 & $\left\{\begin{array}{l}13 \cdot 3 \\
15 \cdot 2\end{array}\right.$ & 215 & $\left\{\begin{array}{l}11.9 \\
13.3\end{array}\right.$ & NS & Yes \\
\hline $75-84$ & 196 & $\left\{\begin{array}{l}14 \cdot 0 \\
15 \cdot 8 \\
17 \cdot 8\end{array}\right.$ & 177 & $\left\{\begin{array}{l}10 \cdot 9 \\
12 \cdot 3 \\
13 \cdot 6\end{array}\right.$ & $P<0.05$ & Yes \\
\hline$\geqslant 85$ & 67 & $\left\{\begin{array}{l}15 \cdot 9 \\
19 \cdot 1 \\
26 \cdot 3\end{array}\right.$ & 54 & $\left\{\begin{array}{l}11 \cdot 2 \\
15 \cdot 3 \\
21 \cdot 8\end{array}\right.$ & NS & Yes \\
\hline Total & 478 & $\left\{\begin{array}{l}13 \cdot 8 \\
15 \cdot 1 \\
16 \cdot 4\end{array}\right.$ & 446 & $\left\{\begin{array}{l}11 \cdot 3 \\
12 \cdot 3 \\
13 \cdot 2\end{array}\right.$ & $P<0.05$ & Yes \\
\hline
\end{tabular}

differed little in the two periods. When the time spent in acute wards plus the time spent in convalescent wards was compared for the two periods, the mean hospital stay was even more significantly reduced in 1977-8. Thus for all women aged over 65 the total hospital stay was reduced from 34 to 18 days, and for women aged over 85 total stay was reduced from 59 to 20 days.

TABLE V-Fate of patients leaving acute wards in the two study periods. Figures are percentages of all patients in each age group

\begin{tabular}{|c|c|c|c|c|c|c|c|c|c|c|}
\hline \multirow{2}{*}{$\underset{\text { group }}{\text { Age }}$} & \multicolumn{2}{|c|}{$\begin{array}{l}\text { Discharged } \\
\text { home }\end{array}$} & \multicolumn{2}{|c|}{ Dead } & \multicolumn{2}{|c|}{$\begin{array}{c}\text { Transferred } \\
\text { to } \\
\text { convalescent } \\
\text { wards }\end{array}$} & \multicolumn{2}{|c|}{$\begin{array}{c}\text { Transferred } \\
\text { to } \\
\text { other } \\
\text { hospital units }\end{array}$} & \multicolumn{2}{|c|}{$\begin{array}{c}\text { Transferred } \\
\text { to } \\
\text { geriatric } \\
\text { department }\end{array}$} \\
\hline & $1975-6$ & $1977-8$ & $1975-6$ & $1977-8$ & $1975-6$ & $1977-8$ & $1975-6$ & $1977-8$ & $1975-6$ & $1977-8$ \\
\hline $\begin{array}{c}65-74 \\
75-84 \\
\geqslant 85\end{array}$ & $\begin{array}{l}65 \cdot 6 \\
51.3 \\
47 \cdot 4\end{array}$ & $\begin{array}{l}72 \cdot 2 \\
52 \cdot 6 \\
45 \cdot 4\end{array}$ & $\begin{array}{l}13.9 \\
28.7 \\
36.8\end{array}$ & $\begin{array}{l}11 \cdot 2 \\
21.9 \\
18 \cdot 2\end{array}$ & $\begin{array}{r}\text { Men } \\
8 \cdot 6 \\
13 \cdot 0 \\
10.5\end{array}$ & $\begin{array}{l}3.9 \\
7.0 \\
4.5\end{array}$ & $\begin{array}{r}10 \cdot 2 \\
5 \cdot 2 \\
0\end{array}$ & $\begin{array}{l}11 \cdot 2 \\
12 \cdot 3 \\
13 \cdot 6\end{array}$ & $\begin{array}{l}1.6 \\
1.7 \\
5.3\end{array}$ & $\begin{array}{r}1 \cdot 4 \\
6 \cdot 1 \\
18 \cdot 2\end{array}$ \\
\hline Total & $60 \cdot 3$ & $65 \cdot 5$ & $19 \cdot 6$ & 14.5 & $10 \cdot 1$ & $4 \cdot 8$ & $8 \cdot 2$ & $11 \cdot 6$ & $1 \cdot 8$ & $3 \cdot 6$ \\
\hline $\begin{array}{c}65-74 \\
75-84 \\
\geqslant 85\end{array}$ & $\begin{array}{l}59 \cdot 3 \\
38 \cdot 8 \\
19 \cdot 4\end{array}$ & $\begin{array}{l}68 \cdot 4 \\
53 \cdot 7 \\
40 \cdot 7\end{array}$ & $\begin{array}{l}12 \cdot 5 \\
21 \cdot 4 \\
28 \cdot 3\end{array}$ & $\begin{array}{l}13.5 \\
20.9 \\
31.5\end{array}$ & $\begin{array}{r}\text { Women } \\
13 \cdot 5 \\
22 \cdot 9 \\
22 \cdot 4\end{array}$ & $\begin{array}{l}8 \cdot 8 \\
9 \cdot 0 \\
5 \cdot 6\end{array}$ & $\begin{array}{r}10 \cdot 0 \\
9 \cdot 7 \\
9 \cdot 0\end{array}$ & $\begin{array}{l}7 \cdot 4 \\
8 \cdot 5 \\
7 \cdot 4\end{array}$ & $\begin{array}{r}4 \cdot 7 \\
7 \cdot 1 \\
20 \cdot 9\end{array}$ & $\begin{array}{r}1.9 \\
7.9 \\
14.8\end{array}$ \\
\hline Total & $45 \cdot 4$ & $59 \cdot 1$ & 18.4 & $18 \cdot 6$ & $18 \cdot 6$ & $8 \cdot 5$ & $9 \cdot 6$ & $7 \cdot 8$ & 7.9 & $5 \cdot 8$ \\
\hline
\end{tabular}

\section{Discussion}

The most obvious help that acute medical wards might expect to receive from a geriatric service is the speedy transfer of elderly patients who do not need the resources of the acute ward but cannot be sent home. The pejorative term "bed blocker" has been applied to such patients and indicates the geriatric service's inability to offer the necessary help in a timely fashion. ${ }^{1}$

The "blocked bed" is well known in Edinburgh, and when the university department of geriatric medicine was opened in 1976 it was agreed that efforts should be made to help acute medical wards, especially in the main teaching hospitals. On the assumption that early attention of doctors from the geriatric 
service might speed the process of mobilisation of some elderly patients, that some patients might be rendered more continent, and that more effective mobilisation of family and community support might be secured it was agreed that consultants in geriatric medicine (and supporting junior staff) should be attached to each of the six medical charges in the largest teaching hospital.

Comparison of two periods of normal working before and after the institution of the scheme showed a reduction in mean and median lengths stay of elderly patients, an increase in the proportion staying two weeks or less, and an increase in the proportion being discharged home. These improvements were most noticeable for women.

The two study periods covered the same eight months of the year; the medical wards were being run on similar lines, and there had been no change in bed numbers or admission policies. At the same time there had been only minor alterations in the number of geriatric beds, so it is unlikely that this had any impact on the figures in the two periods. In any case, the improvement was clearly not due to increased transfers to the geriatric unit, since the proportions transferred were closely similar in the two periods. The total numbers of patients admitted, their age and sex distribution, and the mortality rates were also closely similar for the two samples.

We cannot define exactly the reasons for the improvement but suggest that the following factors are important: (1) obtaining a prompt and complete social report; (2) multidisciplinary assessment of the patient by the doctor, nurse, physiotherapist, occupational therapist, and, of course, the medical social worker; (3) the special interest and experience in the psychiatry of old age that the geriatric team was able to bring to the ward; (4) early planning of arrangements to facilitate return to the community; (5) familiarity of the geriatric medicine team with the local community resources and how to mobilise them; (6) the ability of the geriatric team to arrange directly for geriatric aftercare for patients returned home or, in the case of patients who went outside the team catchment area, to negotiate this with other geria- tric teams in the region. (7) Possibly the most important single factor was the ability of the geriatric medicine specialist to decide when it was safe and suitable for an individual old patient to be returned home once a certain degree of independence had been achieved. This ability arises out of experience and cannot be achieved in any other way. Another similar factor is the weekly review of each elderly patient, even those who seem to be "stuck." Under the previous system once a patient's name had "gone on the long-term list" and been categorised as a "bed blocker," the incentive to go on seeking alternatives tended to slow down or disappear.

Interestingly the improvements observed were much less dramatic in men. This presumably reflects the well-known fact that geriatric medicine is mainly concerned with old women and men do not present the same number or severity of problems. Men usually have wives to care for them, and in any case when affected with acute illness they tend either to get better or to succumb, while their womenfolk often do neither.

This scheme of integration may be commended for many reasons; not the least is that it helps to bring geriatric medicine into the teaching hospital, helps towards integration with general medicine, and permits the application of specifically geriatric skills at a most important point in the management of elderly patients.

We thank Dr J S Milne for advice on analysis and interpretation of data, and Mrs J M Chopin for painstaking and careful collection of figures.

Requests for reprints should be sent to Professor J Williamson.

\section{Reference}

${ }^{1}$ McArdle, C, Wylie, J C, and Alexander, W D, British Medical fournal, 1975, 4, 568.

(Accepted 23 May 1979)
ONE HUNDRED YEARS AGO $\mathrm{M} \mathrm{H}$, aged 18, had always enjoyed good health, although, a year ago, she broke her arm. She was first taken ill while at her work. She suddenly felt a pain in the left breast, which shot up to her head; then a rushing sound in her ears; everything became dark, and she fell. When she returned to consciousness, she found herself in bed. These attacks recurred regularly every half-hour until I saw her two days afterwards. At the time of my first visit, she lay in bed unconscious, and making regular and rhythmical movements with her arms and legs, and also with the muscles of the face; the eyes were squinting and turned upwards. My first impression was that what I saw was the clonic stage of an ordinary epileptic seizure. The temperature, however, was only 98.2 deg., and, on pressing downwards in the left iliac region, she became sensible immediately, and was smiling as if nothing had happened. On resuming the pressure in the same situation, she screamed and became unconscious again, the same clonic movements having also returned with all their original intensity. The pressure again restored her to sensibility. I instructed her mother how to proceed on the occurrence of another fit, and left. Next morning, I was sent for hurriedly, the report being that, on coming out of a fit, she was unable to speak. On visiting her, I found that this was the case; for, even when severely tested, she could not utter a syllable, although she protruded the tongue, and moved it in every direction in her efforts to articulate. In addition, there were loss of hearing on the left side, achromatopsy, and loss of smell and taste, anaesthesia of the left arm and leg, and contracture of the legs. I need scarcely recapitulate all the details of these symptoms, which were those usually noted in hystero-epilepsy. On applying several metals-zinc, iron, copper, silver, platinum, etcthere was no effect produced; but, on placing a sovereign to the left temple, she gradually recovered the perception of colour in the reverse order (as I afterwards found) of its loss. The same metals were then applied to the legs, first to the left and then to the right; sensibility and the power of movement returned in twelve minutes. Again, on placing the sovereigns under the tongue, her speech returned in ten minutes; but gasping efforts to speak began in five minutes after the application of the gold, and these continued until she took a long inspiration and said, "There it is now." Her speech was lost again in half an hour, and each time the gold was applied it was observed that the time taken to recover the sense or faculty was longer. Chloride of gold and sodium were administered internally, and the fits became gradually less frequent and of shorter duration. Occasionally, after a seizure, there were anaesthesia and analgesia; and again, after the next fit, sensibility sometimes returned.

In two weeks after my first visit, the aphasia was still present; but she stated that she had been able to speak for short intervals, and, on the occurrence of a fit, she had lost the power again. I had the gold applied for two hours; it had no effect, and the patient made fruitless efforts to speak. I removed the coins, and applied the continuous current of a battery. In a few minutes, the aphasia disappeared, but not at once; for she had tried to speak several times for the sake of having the battery removed. After this date, electricity was applied whenever there was any loss of sensibility, and with the invariable result of restoring it in a few minutes. At this period, with the view of ascertaining what part, if any, electricity played in the action of the metal, I made some experiments with a delicate astatic galvanometer and Wheatstone's bridge, indicating $1 \mathrm{Ohm}$ in 50000 , using a chromic acid battery. I found that the current given by the sovereigns was so small as scarcely to deflect the needle of the galvanometer. The "resistance" in this patient was very great, and the least amount measured was $142000 \mathrm{Ohms}$, when the electrodes were placed over the radial artery at the wrist. Now, in a number of healthy persons, I have never found this resistance amount to more than $30000 \mathrm{Ohms}$, which is very rare, and in most of them it never was more than 7000 Ohms. During the second month after the first accession of symptoms, the patient had only one fit, the catamenia (which had been absent for three months) returned, the anaesthesia, etc, disappeared altogether. It is now five months since she took any medicine, and during that period has enjoyed very good health. (British Medical fournal, 1879.) 